\title{
Effects of combustion timing on pressure rise rates in a residual effected HCCI engine
}

\begin{abstract}
Realization of a low temperature combustion concept in homogeneous charge compression ignition (HCCI) engines is a cutting-edge technology that offers clean combustion in parallel with high thermal efficiency. Low combustion temperature prevents from NO$O_{x}$ formation whereas homogeneous mixture assures smokeless exhaust. However, achieving the production feasibility by HCCI technology is hampered by high pressure rise rates and the resulting combustion noise at a high load operation. This paper explores combustion timing parameters that are capable of maintaining permissible levels of pressure rise rates under a high load regime. On the basis of experimental data collected at a high load HCCI operation, pressure rise level was correlated with combustion duration. Furthermore, combustion duration has been found to scale with in-cylinder volume, for which 50\% of mass fraction burned appeared. The results showed quantitatively limitations of engine load, pointing out on required combustion timings to achieve acceptable combustion harshness depending on engine load.
\end{abstract}

Key words: $\mathrm{HCCI}$, boost, pressure rise rate

\section{Introduction}

Reciprocating combustion engines are responsible for one third of global $\mathrm{CO}_{2}$ emissions, and moreover pose a high risk due to the presence of toxic components in the exhaust. Nitrogen oxides and particulate matters (PM) are the most dangerous exhaust components. Furthermore these compounds are very difficult to remove from the exhaust using catalytic converters or various types of filters. However, homogeneous charge compression ignition (HCCI) combustion engine allows for realization of the combustion process so that the formation of these components will be minimized. HCCI combustion can be achieved via internal exhaust gas recirculation with the use of so-called negative valve overlap (NVO). This technique consists of trapping exhaust gases from the previous cycle in the cylinder. As a result of compression of the exhaust, air and fuel mixture, oxidation reactions occur simultaneously in the entire volume and at low temperature, which prevents from the formation of nitrogen oxides. At the same time, due to a homogeneous mixture, formation of particulate matters is radically diminished.

Despite of the indisputable advantages of this innovative combustion technique, HCCI combustion systems are still in the research phase. One of the issues to be solved is high pressure rise rate (PRR) inside the cylinder resulting from the volumetric nature of combustion. This form of combustion harshness limits high engine loads. For high PRR pressure pulsations in the combustion chamber are generated, which lead to an increase in noise emitted by the engine and an increase in loads acting on the crankshaft system [15]. The waves, which are generated by the significant PRR, produce a similar effect to knocking combustion [14]. During combustion in a spark ignition engine, the flame is gradually spreading in the combustion chamber. Pressure is also increasing gradually. In the HCCI engine, there is sudden combustion of the entire mixture in the cylinder. This results in a high rates of heat release and high PRRs in the cylinder. PRR reduction can be realized by means of two major methods: increasing fuel dilution and reducing the combustion reaction rates, or combustion retarding via mixture stratification [10].

Dec and Yang [2] applied boost to HCCI engine and heating-up of the intake air for increasing internal energy of the in-cylinder fluid. In addition, the engine was equipped with direct fuel injection into the cylinder. They reached the engine load of $0.88 \mathrm{MPa}$ in indicated mean effective pressure) IMEP at boost pressure of $0.18 \mathrm{MPa}$ and without neither external EGR nor internal EGR. Further increase in the intake pressure caused exceeding the combustion harshness limit.

Kulzer et al. [9] applied single fuel injection during the NVO period and boost pressure of up to $0.3 \mathrm{MPa}$. The authors noted that an increase of the in-cylinder charge dilution by air provides a substantial, simultaneous reduction of PRR and the $\mathrm{NO}_{\mathrm{x}}$ emission. However, at high boost pressures the compressor energy demand could consume the advantage of higher thermal efficiency of the HCCI working process [8].

Canakci [1] and Yap et al. [17] applied relatively low boost of up to $0.14 \mathrm{MPa}$ to gasoline port injected engines. It was observed that boosting enabled a substantial reduction of the $\mathrm{NO}_{\mathrm{x}}$ emission, while excessive PRR was noted. Scaringe et al. [11] also reported an increase in PRR at higher boost pressures. They noted that the high load limit under PRR constant cannot be extended by the alternating method of fuel dilution i.e. EGR rate versus air-excess ratio. Wildman et al. [16] reasoned that boost cannot improve the engine output, because high load limit of HCCI engine is constrained by PRR rather than fresh air aspiration limitations.

Dec et al. [3] applied the direct fuel injection and the port fuel injection in order to create partially fuel stratification. It has been observed that increasing the fuel split ratio was capable of PRR reduction. However, this method was effective only for highly boosted engine operation. Turkcan et al. [13] in their research applied solely direct fuel injec- 
tion and split injection technique in the HCCI engine. In the first stage $4 / 5$ of fuel was injected early during the intake phase to create a premixed charge. Whereas the remaining $1 / 5$ fuel dose was introduced directly during the compression stroke. The authors observed that the retarded secondary injection timings caused a reduction in PRR.

Hunicz et al. [7] investigated the effects of various injection strategies and different fuel dose divisions under variable boost pressure. The authors noted that stratification is an effective measure to reduce both the PRR and $\mathrm{NO}_{\mathrm{x}}$ emissions. Nevertheless, as in the case of the abovementioned experimental studies, the results showed a trade-off between the $\mathrm{NO}_{\mathrm{x}}$ and $\mathrm{CO} / \mathrm{HC} / \mathrm{PM}$ emissions. Recent work by Hunicz and Mikulski [4] has shown that PRR can be effectively controlled via variation in mass of fuel injected during the NVO period for reforming. This technique enabled effective control of fuel reactivity [5] and also provided the substantial thermal effects [6].

Present paper further explores limitations of HCCI engine operation that come from combustion timing parameters. On the basis of large number of experimental data this study indicated required combustion timing indexes to achieve acceptable PRR levels depending on engine load.

\section{Experimental test stand and research conditions}

The experiments were performed on single-cylinder research engine reinstalled in new laboratories at Lublin University of Technology (Fig. 1). The combustion system that enabled HCCI operation comprised bowl-shaped combustion chamber located in the cylinder head and a sidemounted swirl-type, single-stream, electromagnetic gasoline injector. Supercharging was provided by an externally driven compressor with air temperature conditioning system. Furthermore, a hydraulic variable valve actuation system enabled an independent adjustment of intake and exhaust valve opening phases and lifts. During the research the valvetrain was set to achieve NVO and thus enabled HCCI combustion. The detail data of the test engine, along with the valvetrain settings that were used in the present research are shown in Table 1.

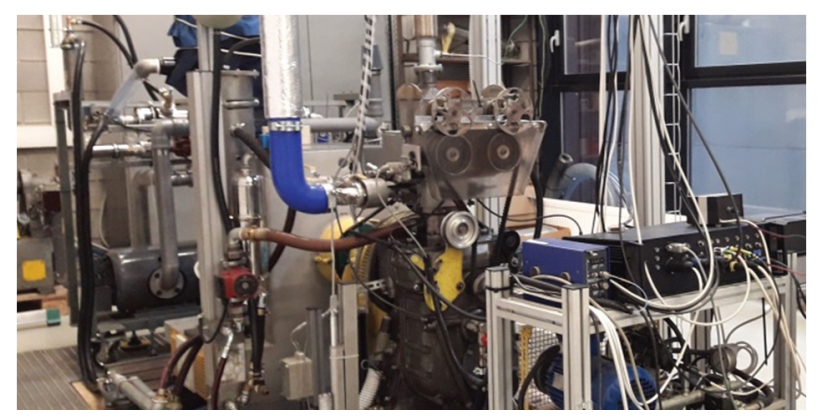

Fig. 1. Experimental test stand

The research engine was coupled to a direct current dynamometer with automatic speed control. The system automation also included a thermal air mass flow meter, a fuel balance and a set of pressure and temperature transducers for monitoring of all media conditions. The excess air ratio $(\lambda)$ was measured with the use of LSU 4.2 Bosch lambda probe and ETAS lambda meter.
Combustion thermodynamic analysis was performed using AVL BOOST software, where measured in-cylinder pressure was used as input data. To provide this signal a GH12D miniature pressure transducer from AVL was installed directly in the engine head and connected via charge amplifier to the test bench acquisition system. The PC-based high speed pressure recording system was triggered by an optical encoder with resolution of 3600 pulses per crankshaft revolution and acquired signals from 100 cycles.

Table 1. Research engine parameters

\begin{tabular}{|l|c|c|}
\hline Parameter & Unit & Value \\
\hline Displaced volume & $\mathrm{cm}^{3}$ & 498.5 \\
\hline Bore & $\mathrm{mm}$ & 84 \\
\hline Stroke & $\mathrm{mm}$ & 90 \\
\hline Compression ratio & - & 11.7 \\
\hline No of valves & - & 2 \\
\hline Intake valve opening location & ${ }^{\circ} \mathrm{CA}$ aTDC & 80 \\
\hline Intake valve opening duration & ${ }^{\circ} \mathrm{CA}$ aTDC & 130 \\
\hline Intake valve lift & $\mathrm{mm}$ & 3.6 \\
\hline Exhaust valve opening location & ${ }^{\circ} \mathrm{CA}$ aTDC & 520 \\
\hline Exhaust valve opening duration & ${ }^{\circ} \mathrm{CA}$ aTDC & 119 \\
\hline Exhaust valve lift & $\mathrm{mm}$ & 2.9 \\
\hline
\end{tabular}

The engine was fueled with pump-grade gasoline with 95 research octane number. All experiments were performed at a single rotational speed of $1500 \mathrm{rev} . / \mathrm{min}$. The experimental matrix comprised boost pressure sweeps from naturally aspirated conditions to approximately $0.15 \mathrm{MPa}$ intake pressure. Intake temperature was kept constant at $30^{\circ} \mathrm{C}$, whereas engine cooling liquid temperature was maintained at $90^{\circ} \mathrm{C}$. The boost pressure sweeps were repeated for various injection schemes that provided different degrees of fuel reactivity (achieved via NVO injection) and different degrees of stratification (achieved via late fuel injection). Additionally, three overall fuel quantities were applied providing net IMEPs at levels of $0.42 \mathrm{MPa}, 0.58$ $\mathrm{MPa}$, and $0.71 \mathrm{MPa}$. During the research nearly 100 engine operating points were investigated in terms of thermodynamic analysis. Combustion timing parameters were derived from cumulative heat release curves. Pressure rise rate was calculated as a ratio of pressure differences between $95 \%$ mass fraction burned (MFB) and 5\% MFB, and the 5\%-95\% MFB angular duration.

\section{Results}

Figure 2 shows a series of in-cylinder pressure traces for moderate IMEP and variable intake pressure. It can be noted that increase of boost pressure advances autoignition. However, PRRs apparently stabilize. To provide more details Fig. 3 shows heat release rate (HRR) curves for the same set of data. It can be noted that for the examined boost sweep the peak HRR was more than doubled in parallel with substantial auto ignition advance. Namely, an increase in the boost pressure by $0.03 \mathrm{MPa}$ resulted in an increase in HRR from 40 to $100 \mathrm{~J} /{ }^{\circ} \mathrm{CA}$. In addition, location of the maximum HRR was advanced by $15^{\circ} \mathrm{CA}$. It 
indicates that timing of maximum reaction rate and combustion duration are correlated in a way that at small volumes reaction rate is higher.

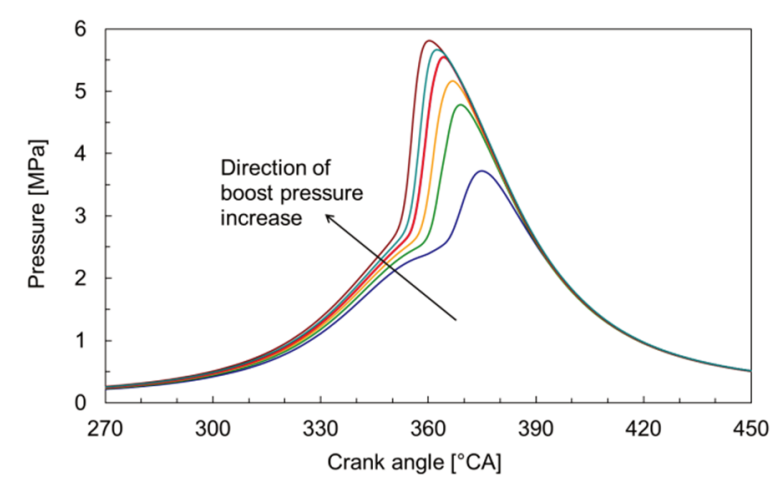

Fig. 2. In-cylinder pressure at IMEP $\approx 0.58 \mathrm{MPa}$ for boost pressure between $0.11 \mathrm{MPa}$ and $0.14 \mathrm{MPa}$

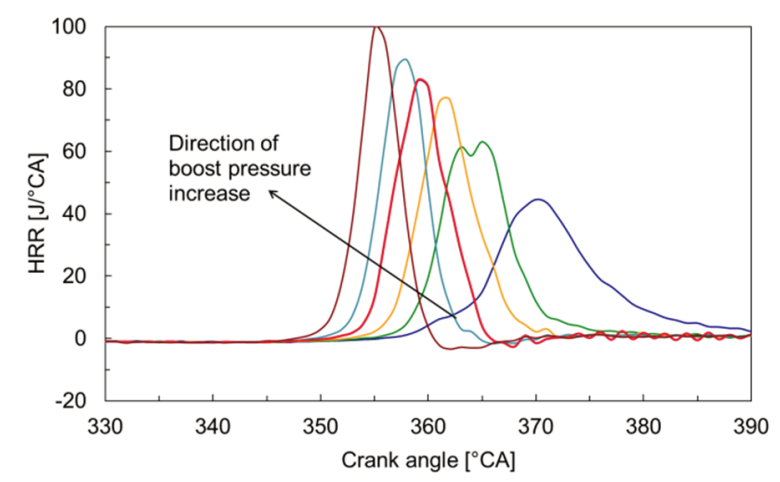

Fig. 3. Heat release rates at IMEP $\approx 0.58 \mathrm{MPa}$ for boost pressure between $0.11 \mathrm{MPa}$ and $0.14 \mathrm{MPa}$

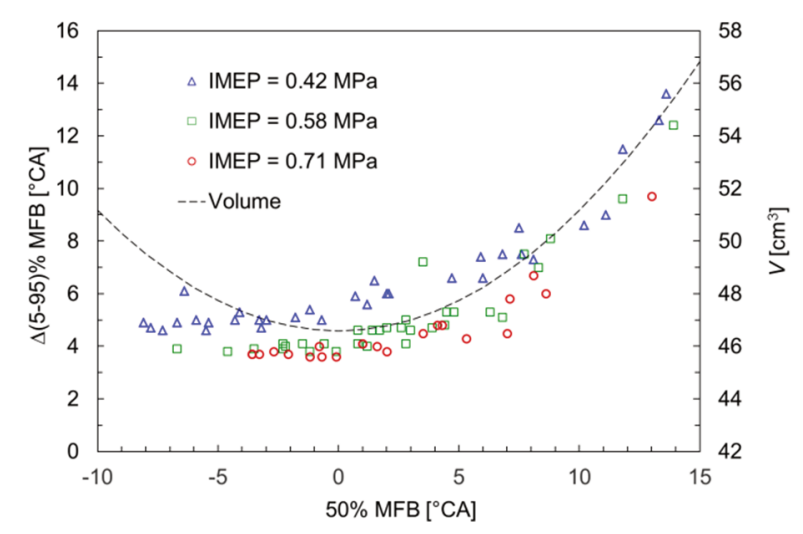

Fig. 4. Combustion duration expressed as period between $5 \%$ and $95 \%$ MFB as a function of location of $50 \%$ MFB for all investigated conditions. Dotted line shows in-cylinder volume

The correlation between combustion duration and combustion timing parameters for all investigated conditions are provided in Fig. 4. Additionally, Fig. 4 includes scaled incylinder volume curve, showing that combustion duration correlates with a volume, however only if the center of combustion takes place after TDC. Thus, the larger combustion chamber volume for retarded combustion, the lower reaction rate. Additionally, it was noted by Sjöberg et al. [12] that retarding the combustion phasing reduces the
HRR by amplifying the benefit of the naturally occurring thermal stratification. It can also be observed from Fig. 4 that increase in fueling increases combustion rates.

The in-cylinder pressure change resulting from combustion theoretically can be calculated using the first law of thermodynamics

$$
\Delta \mathrm{p}=\frac{1}{\mathrm{~V}}[\Delta \mathrm{Q}(\gamma-1)-\gamma \cdot \mathrm{p} \cdot \Delta \mathrm{V}]
$$

where: $\mathrm{V}$ is a volume of the cylinder, $\Delta \mathrm{Q}$ is a gross heat release rate and $\gamma$ is a ratio of specific heats. PRR in HCCI engine can be expressed with relatively high accuracy even if the Eq. 1 is simplified. Namely, heat transfer can be ignored as well as volumetric expansion term can be neglected, because combustion is quick, thus takes place at almost constant volume. Considering the above, the pressure rise rate can be estimated by the following formula:

$$
\mathrm{PRR} \approx \frac{(\gamma-1) \cdot \mathrm{Q}}{\mathrm{V} \cdot \Delta(5-95) \% \mathrm{MFB}},
$$

where $\mathrm{Q}$ is the amount of chemical energy provided with the fuel. In-cylinder volume in Eq. 2 can be considered constant and its value at 50\% MFB point can be used.

As can be noted from Eq. 2 the combustion duration is a leading factor affecting PRR. Figure 5 shows the dependence of PRR on combustion duration. It can be noted that PRR increase progressively with increasing reaction rates for all investigated conditions. Obviously, it can be observed that the increase in the load causes the increase in PRR. However the effect of the amount of chemical energy would be diminished by the trade-off between 50\% MFB location and reaction rate, as shown in Fig. 4.

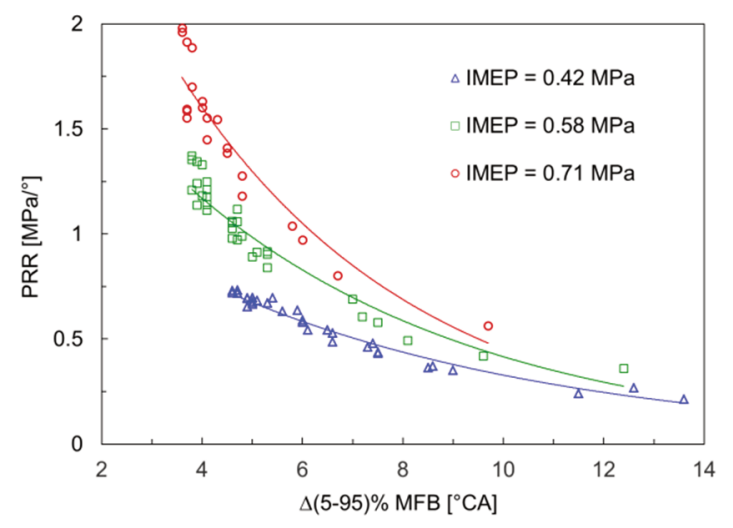

Fig. 5. Pressure rise rates as a function of combustion duration for all investigated conditions

It should be noted that for HCCI combustion, the rate of pressure increase should not exceed the range 0.5$0.7 \mathrm{MPa} /{ }^{\circ} \mathrm{CA}$ [17]. Increase of the PRR beyond this limit causes the engine knock. For the highest applied load it is hardly possible to meet the harshness limit, what requires advanced control strategies to increase the reaction rate, i.e. optimized valve timings and reduction of boost pressure. However, it was shown in [4] that this strategy increases $\mathrm{NO}_{\mathrm{x}}$ emissions. For IMEP $=0.41 \mathrm{MPa}$ the limit can be easily met, allowing to optimize combustion in terms of emissions and efficiency. For average investigated load of 
$\mathrm{IMEP}=0.58 \mathrm{MPa}$, achieving acceptable $\mathrm{PRR}$ requires extension of combustion duration to $7-8^{\circ} \mathrm{CA}$.

Moreover in order to consider volume factor, Fig. 6 shows PRRs as functions of the inverse of combustion duration and a volume at 50\% MFB for all investigated conditions. It can be noted that the measurement points are arranged linearly, depending on the IMEP. Some scattering of the points can result from variable thermal efficiency, that requires different fuel's energy to achieve given IMEP.

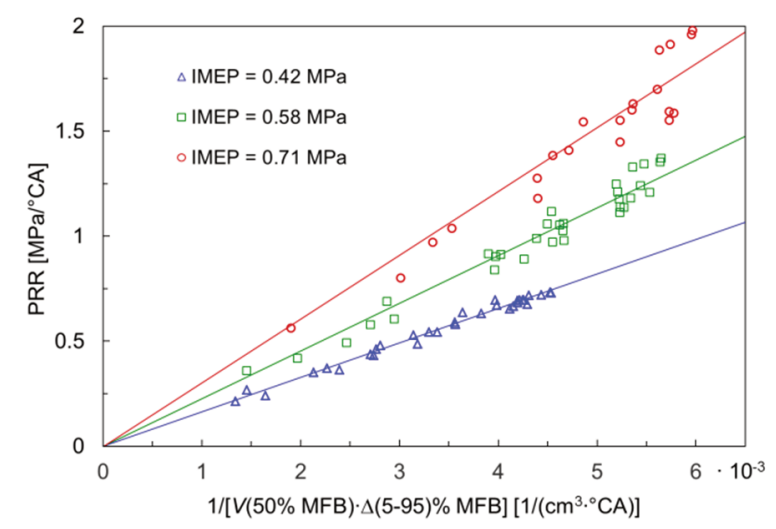

Fig. 6. Pressure rise rates as a function of the inverse of combustion duration and volume at 50\% MFB for all investigated conditions

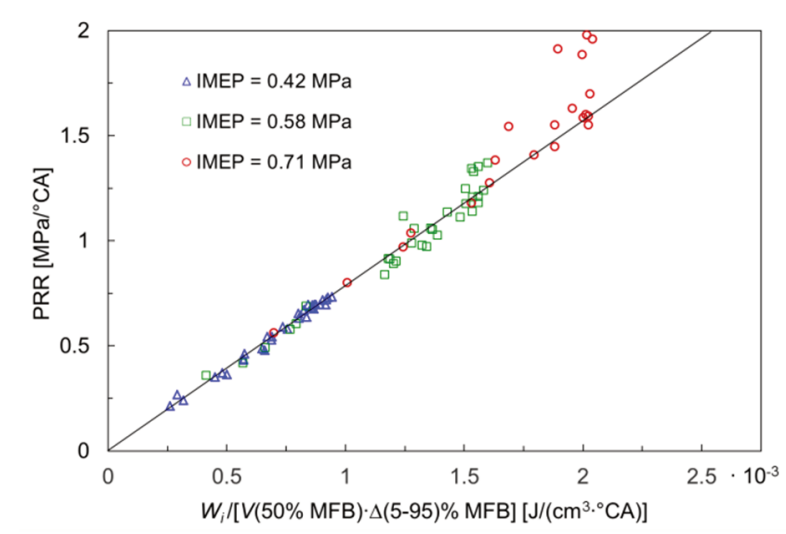

Fig. 7. Pressure rise rates as a function of the indicated work divided by combustion duration and volume at 50\% MFB for all investigated conditions

The result of the regression with a full set of variables, including indicated work $\left(\mathrm{W}_{\mathrm{i}}\right)$ is shown in Fig. 7. Such a presentation of the data shows the boundary combustion timing parameters required to achieve acceptable PRR level. For the highest engine load there is some number of operating points above the trend line. It can be attributed to an increase of specific heats ratio, because EGR decreases at high amounts of fuel and heavy boost.

\section{Conclusions}

This paper explored combustion timing parameters that are capable of maintaining permissible levels of pressure rise rates under high load regime of HCCI engine. The experimental matrix included various valvetrain settings, direct fuel injection strategies and boost pressures. The results led the authors to draw the following conclusions:

1. Combustion duration has been found to scale with incylinder volume, for which $50 \%$ of mass fraction burned appeared. This correlation occurs only if the $50 \%$ mass fraction burned of combustion takes place after TDC. It indicates that these two measures to reduce PRR work simultaneously.

2. Increase of fueling reduces reaction time that further contributes to increase PRRs at high engine load regime.

3. For investigated conditions the range of attainable combinations of $50 \%$ MFB and combustion durations were the same for all three quantities of fuel. Moreover these combustion timing parameters appear to be a boundary of HCCI operation.

4. Among investigated conditions, only case of IMEP = $0.41 \mathrm{MPa}$ provided acceptable combustion harshness over a wide range of control parameters, enabling combustion optimization in terms of emissions and thermal efficiency. For IMEP $=0.58 \mathrm{MPa}$ only few cases laid below the threshold of $0.7 \mathrm{MPa} /{ }^{\circ} \mathrm{CA}$.

5. The results clearly indicate that high load HCCI operation limits result almost solely from fuel quantity. Utilization of other measures to reduce PRR can widen operating range in much lesser extent.

6. Further investigations into widening HCCI operation mode towards high loads should be focused on reduction of reaction rates via higher fuel dilution and wider spread of mixture reactivity control by variations of NVO fuel injection.

\section{Acknowledgements}

This work was funded by the National Science Centre of Poland, under the grant No. 2015/17/B/ST8/03279. The authors wish to thank AVL List GmbH for making simulation software available within a framework of AVL University Partnership Program.

\section{Nomenclature}

CA crank angle

EGR exhaust gas recirculation

$\mathrm{HC}$ hydrocarbons

HCCI homogeneous charge compression ignition

HRR heat release rate

IMEP indicated mean effective pressure

MFB mass fraction burned

$\mathrm{NO}_{\mathrm{x}}$ nitrogen oxides

NVO negative valve overlap $\mathrm{p} \quad$ pressure

PM particulate matter

PRR pressure rise rates

Q energy

TDC top dead center

$\mathrm{V}$ volume

$\mathrm{W}_{\mathrm{i}} \quad$ indicated work

$\gamma \quad$ ratio of specific heats 


\section{Bibliography}

[1] CANAKCI, M. Combustion characteristics of a DI-HCCI gasoline engine running at different boost pressure. Fuel. 2012, 96, 546-555. DOI:10.1016/j.fuel.2012.01.042.

[2] DEC, J.E., YANG, Y. Boosted HCCI for high power without engine knock and with ultra-low $\mathrm{NO}_{\mathrm{x}}$ emissions - using conventional gasoline. SAE International Journal of Engines. 2010, 3, 750-767. DOI:10.4271/2010-01-1086.

[3] DEC, J.E., YANG, Y., DRONNIOU, N. Boosted HCCI controlling pressure-rise rates for performance improvements using partial fuel stratification with conventional gasoline. SAE International Journal of Engines. 2011, 4(1), 1169-1189. DOI:10.4271/2011-01-0897.

[4] HUNICZ, J., MIKULSKI, M. Application of variable valve actuation strategies and direct gasoline injection schemes to reduce combustion harshness and emissions of boosted HCCI engine. Journal of Engineering for Gas Turbines and Power. 2019, 141(7). DOI:10.1115/1.4043418.

[5] HUNICZ, J. An experimental study into the chemical effects of direct gasoline injection into retained residuals in a homogeneous charge compression ignition engine. International Journal of Engine Research. 2016, 17(10), 10311044. DOI:10.1177/1468087416636492.

[6] HUNICZ, J., MIKULSKI, M. Investigation of the thermal effects of fuel injection into retained residuals in HCCI engine. Applied Energy. 2018, 228, 1966-1984, DOI:10.1016/ j.apenergy.2018.07.075.

[7] HUNICZ, J., TMAR, A., KRZACZEK, P. Effects of mixture stratification on combustion and emissions of boosted controlled auto-ignition engines. Energies. 2017, 10(12), 2172. DOI:10.3390/en10122172.

[8] HYVÖNEN, J., HARALDSSON, G., JOHANSSON, B. Supercharging HCCI to extend the operating range in a multi-cylinder VCR-HCCI engine. SAE Technical Paper 200301-3214. 2003. DOI:10.4271/2003-01-3214.

[9] KULZER, A., NIER, T., KARRELMEYER, R. A thermodynamic study on boosted HCCI: Experimental results. SAE

\author{
Jacek Hunicz, DSc., DEng. - Faculty of Mechanical \\ Engineering, Lublin University of Technology. \\ e-mail: j.hunicz@pollub.pl
}

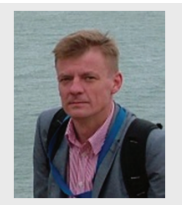

Michał Gęca, MEng. - Faculty of Mechanical Engineering, Lublin University of Technology.

e-mail: michal.geca@pollub.pl
Technical Paper 2011-01-0905. 2011. DOI:10.4271/201101-0905.

[10] KWON, O.S., JEONG, D.W., LIM, O.T., LIDA, N. The research about thermal stratification effect on pressure rise rate in supercharged HCCI engine based on numerical analysis. SAE Technical Paper 2009-32-0141. 2009.

[11] SCARINGE, R.J., WILDMAN, C., CHENG, W.K. On the high load Limit of boosted gasoline HCCI engine operating in NVO mode. SAE International Journal of Engines. 2010, 3, 35-44. DOI:10.4271/2010-01-0162.

[12] SJÖBERG, M., DEC, J.E., CERNANSKY, N.P. The potential of thermal stratification and combustion retard for reducing pressure-rise rates in $\mathrm{HCCI}$ engines, based on multi-zone modeling and experiments. SAE Technical Paper 2005-010113. 2005. DOI:10.4271/2005-01-0113.

[13] TURKCAN, A., OZSEZEN, A.N., CANAKCI, M. et. al. An experimental and modeling study to investigate effects of two-stage direct injection variations on HCCI combustion. Combustion Science and Technology. 2015, 187(4), 642658. DOI:10.1080/00102202.2014.960562.

[14] VRESSNER, A. et al. Pressure oscillations during rapid HCCI combustion. SAE Technical Paper 2003-01-3217. 2003. DOI:10.4271/2003-01-3217.

[15] WESTBROOK, C.K. et al. The autoignition chemistry of paraffinic fuels and pro-knock and anti-knock additives: a detailed chemical kinetic study. SAE Technical Paper 912314. 1991. DOI:10.4271/912314.

[16] WILDMAN, C., SCARINGE, R.J., CHENG, W.K. On the maximum pressure rise rate in boosted HCCI operation. SAE Technical Paper 2009-01-2727. 2009. DOI:10.4271/200901-2727.

[17] YAP, D., WYSZYNSKI, M.L., MEGARITIS, A., XU, H. Applying boosting to gasoline HCCI operation with residual gas trapping. SAE Technical Paper 2005-01-2121. 2005. DOI:10.4271/2005-01-2121.

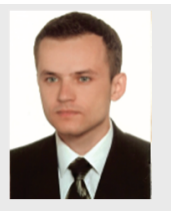

Paweł Kordos, DEng. - Faculty of Mechanical Engineering, Lublin University of Technology. e-mail:p.kordos@pollub.pl

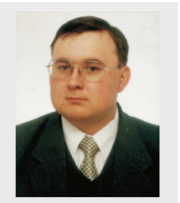

Arkadiusz Rybak, MEng. - Faculty of Mechanical Engineering, Lublin University of Technology. e-mail:a.rybak@pollub.pl 